\title{
Determination of Catechin Compounds in Korean Green Tea Infusions under Various Extraction Conditions by High Performance Liquid Chromatography
}

\author{
Won Jo Cheong, "Moon Hee Park, Gyoung Won Kang, Joung Ho Ko, and You Jin Seo \\ Department of Chemistry and Institute of Basic Research, Inha University, Incheon 402-751, Korea \\ *E-mail: wjcheong@inha.ac.kr \\ Received February 16, 2005
}

\begin{abstract}
Liquid chromatographic methods with UV and fluorescence detection have been used to determine the levels of (+)-catechin, (-)-epicatechin, (-)-epicatechin gallate, and (-)-epigallocatechin gallate in Korean green tea infusions. The extracts of Korean green tea leaves or powders in water at various temperatures $\left(100^{\circ} \mathrm{C}, 80^{\circ} \mathrm{C}\right.$, $60{ }^{\circ} \mathrm{C}$ ) and time, were washed with chloroform and re-extracted to ethyl acetate. The ethyl acetate phase was dried and re-dissolved in methanol and analyzed. Five catechin compounds were separated by gradient elution. The flavonoids were found decomposed on prolonged extraction, thus exhaustive extraction by a Soxhlet apparatus was found useless for green tea. Some unknown components were found in the extracts at $100{ }^{\circ} \mathrm{C}$. When the green tea was filtered and re-extracted with new fresh water, still some flavonoids were extracted. However, the contents of flavonoids in the third extract were found negligible. The flavonoid extraction rate of green tea powders was higher than that of green tea leaves, but flavonoid decomposition of green tea powders was also faster than that of green tea leaves. The traditional way of drinking green tea was found appropriate in view of flavonoids intake.
\end{abstract}

Key Words : Korean green tea, Flavonoids, Extraction time and temperature, Multiple extraction, UV and fluorescence detection

\section{Introduction}

It is well known that about $2 \%$ of the materials formed by photosynthesis in the plant body is transformed to flavonoids. ${ }^{1}$ Flavonoids are present in roots, stalks, leaves, fruits, and anywhere in green plants. The role of flavonoids in the plant body is to protect itself from ultraviolet lights and bacteria. ${ }^{2}$ A flavonoid called "chalcone" is formed first in the plant body, and is transformed to various flavonoids such as flavonone, flavone, flavonol, catechin, epicatechin, etc. ${ }^{3}$ Many natural flavonoids exist in glycosides because glycosides are chemically more stable and more soluble in water, and easier to be stored in the aqueous space of the plant cell.

The structure of flavonoids is based on a C6-C3-C6 skeletal where two phenyl rings are connected via a unit composed of three carbons. Two or more hydroxyl groups are attached to each phenyl ring, thus flavonoids are classified as polyphenolic compounds. Polyphenolic compounds present in various natural foods are known to show some health-enhancing effects such as antibacterial, ${ }^{4}$ antioxidative, ${ }^{5-7}$ anti-tumor and/or anti-cancer activities, ${ }^{8-11}$ and prevention of heart diseases. ${ }^{12-14}$ The exact mechanisms and clear evidences for health-enhancing effects have not been provided yet, but some more convincing results have recently shown up. ${ }^{15-17}$

The types and relative amounts of flavonoids formed in the plant body are related to the evolution of plants, and the flavonoid profile (distribution pattern) is used for verification of classes of bean plants ${ }^{18,19}$ and citrus plants. ${ }^{20-23}$

The typical method of analyzing flavonoids of plants is extracting them by alcohol/water mixed solvents and removing nonpolar components by a water- immiscible solvent such as chloroform, and by concentrating the main solution followed by identifying with UV/VIS, NMR, and Mass Spectrometry for a pure flavonoid, or with TLC and LC for a mixture. ${ }^{3}$

Methods of using a fluorescence detector and/or fluorescence enhancing reagents have been reported since many flavonoids are fluorescent. ${ }^{24-26} \mathrm{GC} / \mathrm{MS}$ methods have also been used, but derivatization is generally required since most flavonoids are nonvolatile, and the number of flavonoids analyzable without derivatization is very limited. ${ }^{27-29}$ LC/MS has recently shown up to be a very promising analytical method of flavonoids. ${ }^{30-32}$

Recently, there have been lots of study on identification and determination of flavonoids in teas by HPLC and CE with various detection methods. ${ }^{33-39}$

The purpose of this study is to determine types and amounts of flavonoids in Korean green tea by both UV and fluorescence detection, and to examine the extraction efficiency of flavonoids by hot water with respect to extraction time and temperature.

\section{Materials and Methods}

Chemicals and Apparatus. HPLC grade water and acetonitrile were purchased from Fisher (Pittsburg, PA, USA) and used without further purification. The five standard compounds, $(+)$-catechin (C), (-)-epicatechin (EC), (-)-epicatechin gallate (ECG), (-)-epigallocatechin (EGC), (-)-epigallocatechin gallate (EGCG) were obtained from Sigma (Steinheim, Germany). Their structures are given in 
<smiles>Oc1cc(O)c2c(c1)OC(c1ccc(O)c(O)c1)C(O)C2</smiles>

(+)-Catechin (C)<smiles>Oc1cc(O)c2c(c1)OC(c1ccc(O)c(O)c1)C(O)C2</smiles>

(-)-Epicatechin (EC)<smiles>Oc1cc(O)c2c(c1)OC(c1cc(O)c(O)c(O)c1)C(O)C2</smiles>

(-)-Epigallocatechin (EGC)<smiles>O=C(O[C@H]1Cc2c(O)cc(O)cc2O[C@H]1c1ccc(O)c(O)c1)c1cc(O)c(O)c(O)c1</smiles><smiles>O=C(O[C@H]1Cc2c(O)cc(O)cc2OC1c1cc(O)c(O)c(O)c1)c1cc(O)c(O)c(O)c1</smiles>

(-)Epicatechin gallate (ECG) (-)Epigallocatechin gallate (EGCG)

Figure 1. The structures of five catechin compounds.

Figure 1. The green tea products (leaves and powders) were manufactured in 2003 by Taepyoungyang Co. from the raw material produced in the Hanra Mountain, Cheju Island, Korea.

A chromatographic system composed of two Shimadzu (Tokyo, Japan) 10AD pumps, a Rheodyne (Cotati, CA, USA) 7520 injector with a $0.5 \mu \mathrm{L}$ internal sample loop, a Samsung (Suwon, Korea) SLC-200 UV/VIS detector, and a Shimadzu DGU-14A degasser was used. An Alltima C18 microcolumn $(0.5 \mathrm{~mm} \times 300 \mathrm{~mm}, 5 \mu)$ was packed in the lab for chromatographic separation. A regular C18 column (4.6 $\mathrm{mm} \times 300 \mathrm{~mm}, 5 \mu$ ) was packed and used when a Shimadzu RF-535 fluorescence detector was incorporated to the chromatographic system. The chromatographic data were obtained by a PC system, and a software Multichro 2000 from Youlin-Gisul (Sungnam, Korea) was used to acquire and process the data.

Chromatographic Separation of 5 Standard Catechin Compounds. Five stock solutions were made by dissolving $1.00 \mathrm{mg}$ of an individual standard material in $1.00 \mathrm{~mL}$ methanol and stored in a refrigerator at $4{ }^{\circ} \mathrm{C}$. A small amount of each stock solution was taken and the 5 aliquots were mixed and diluted to give a wide range of standard mixtures.

The optimized gradient elution program is shown in Figure 2. The solvent A was 50/50 vol\% acetonitrile/water with $0.1 \%$ trifluoroacetic acid (TFA), and the Solvent B, $5 / 95$ vol $\%$ acetonotrile/water with $0.1 \%$ TFA. The flow rate was $0.02 \mathrm{~mL} / \mathrm{min}$ and the detection wavelength was $280 \mathrm{~nm}$.

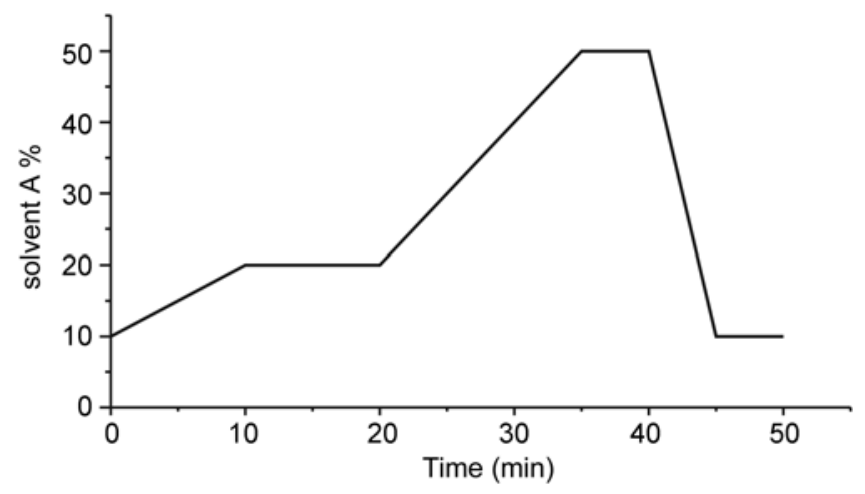

Figure 2. The program of gradient elution for separation of flavonoid standards. The solvent A was $50 / 50$ vol\% acetonitrile/ water with $0.1 \%$ trifluoroacetic acid (TFA), and the Solvent B, 5/95 vol $\%$ acetonotrile/water with $0.1 \%$ TFA.

Extraction of Catechin Components from Green Tea.

Extraction by a Plain Reflux Apparatus: An exact amount of $250 \mathrm{~mL}$ distilled water was poured into a $500 \mathrm{~mL}$ three neck round bottom flask with a reflux condenser, a thermometer, and a glass stopper, and an oil bath over a magnetic hot plate was placed below the flask. The bottle was heated and allowed to be in temperature equilibrium at 60,80 , or $100{ }^{\circ} \mathrm{C}$. An exact amount of $5.00 \mathrm{~g}$ green tea leaves or powders was transferred in the flask, and extraction took place while stirring. An exact amount of $0.900 \mathrm{~mL}$ supernatant solution was taken when the elapsed time was $5,10,20,30,40,60,80,100,120,150,180$, and $240 \mathrm{~min}$. The sampled extract was filtered through a $0.45 \mu$ membrane filter to remove dispersed minute green tea powders.

The sample was washed with $0.90 \mathrm{~mL}$ chloroform in a separatory funnel to remove caffeine, pigments, and other nonpolar impurities. This step was repeated three times and negligible catechin compounds were found in the chloroform phase owing to their low solubility in chloroform. Next, the catechin compounds in the water phase were extracted to $0.90 \mathrm{~mL}$ ethyl acetate, and this step was also repeated three times. Now, negligible catechin compounds were found in the water phase. The ethyl acetate phase was evaporated to dryness and dissolved in $0.300 \mathrm{~mL}$ methanol and injected for chromatographic analysis.

Extraction by a Soxhlet Apparatus: The purpose of using a Soxhlet Apparatus was to determine the content of each flavonoid in the green tea by exhaustive extraction if the flavonoids would be stable. Unfortunately, it ended a failure because the flavonoids were found unstable.

An exact amount of $5 \mathrm{~g}$ green tea was extracted by 250 $\mathrm{mL}$ distilled water. The temperature was fixed to the boiling point of water to secure Soxhlet action, and heating was continued until the siphon fluid changed colorless to indicate that all the flavonoids were extracted.

Determination of Catechin Compounds in the Green Tea Infusions.

Qualitative Determination: The chromatogram of a standard mixture was obtained by the gradient elution as 
described in Figure 2. The chromatogram of an extracted sample was obtained under the same chromatographic condition, and the retention times were compared to those of the standard mixture to identify the corresponding flavonoids. The flavonoid was confirmed by spiking the standard component in the extract. Four flavonoids were identified in the Korean green tea extracts with the UV/VIS detector. They were (+)-catechin, (-)-epicatechin, (-)-epicatechin gallate, (-)-epigallocatechin gallate.

Quantitative Determination: The concentration range of each flavonoid in the green tea extracts was roughly measured in the preliminary experiments, and the concentrations of individual components were determined based on the chromatographic data of a standard mixture. The calibration curves (peak area count vs. concentration) for individual flavonoids were obtained for a wide concentration range, and good linear relationships were observed for all the calibration curves. All the extract samples under various extraction conditions were quantitatively analyzed one by one.

Determination of Flavonoids by a HPLC System with Fluorescence Detection. Epicatechin, epicatechin gallate, epigallocatechin gallate were identified and determined in the green tea extracts by the HPLC-UV system. Fluorescence detection was used for catechin and epicatechin. The proper excitation wavelength was found $235 \mathrm{~nm}$, and the emission wavelength, $315 \mathrm{~nm}$.

\section{Results and Discussion}

Identification of Flavonoids in the Green Tea Infusions by HPLC-UV. Epicatechin, epicatechin gallate, epigallocatechin gallate were identified in the green tea extracts by the HPLC-UV system. Catechin was also detected, but it was overlapped with some impurity peaks and was unable to be quantitatively determined. The chromatogram of the mixture of five standard catechin compounds (400 ppm) and the chromatogram of the green tea extract at $100{ }^{\circ} \mathrm{C}$ for 30 min are comparatively shown in Figure 3.

Quantitative Determination of Flavonoids in the Green Tea Infusions by HPLC-UV. The calibration curves of standard flavonoids are given in Figure 4. Good linear relationships were observed for all the flavonoids. The variations of concentrations of epicatechin, epicatechin gallate, epigallocatechin gallate in the extracts of green tea leaves with respect to extraction time and temperature are shown in Figure 5. The scale of $Y$ axis of Figure 5 represents the concentration of the flavonoid in the original extract ( 250 $\mathrm{mL}$ ) from $5 \mathrm{~g}$ green tea leaves.

The concentration of each flavonoid increased with extraction time, reached the maximum when about $30 \mathrm{~min}$ elapsed, and decreased afterwards. Such a phenomenon implies that the catechin compounds decompose when exposed to hot water long enough.

There are some differences in variation trends among the flavonoids. In the case of epicatechin, the maximum concentration was reached in a similar extraction time at 80
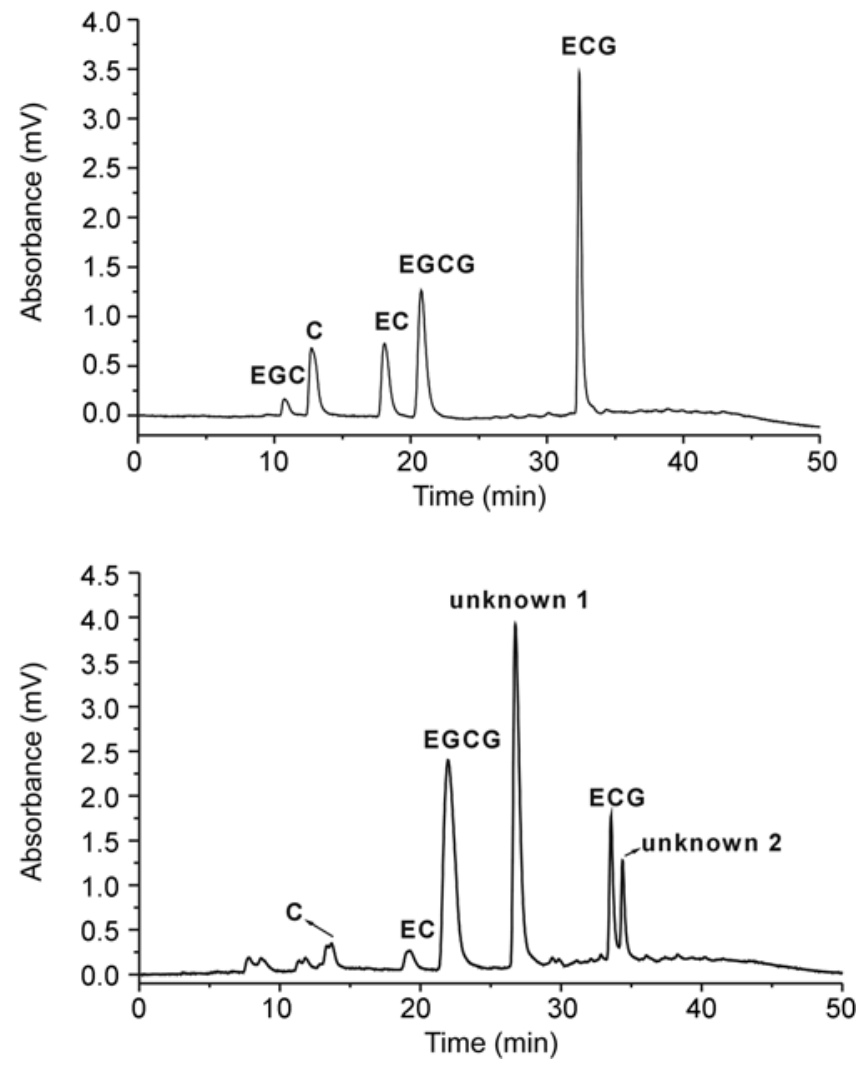

Figure 3. The chromatograms of five standard catechin compounds $(400 \mathrm{ppm})$ and green tea extracts (at $100^{\circ} \mathrm{C}$ for $30 \mathrm{~min}$ ) by UV detection.

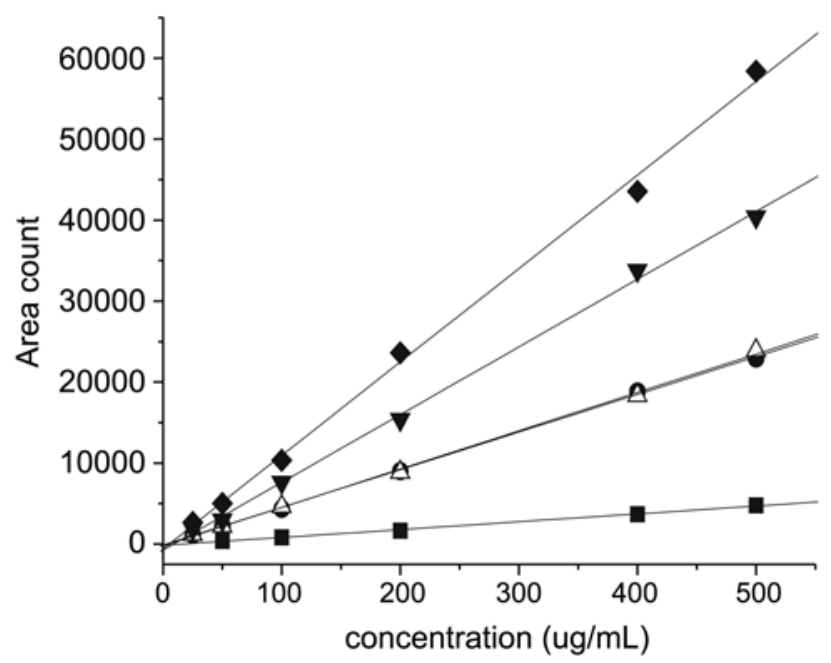

Figure 4. The calibration curves of standard catechin compounds by HPLC-UV system. ( $)(-)$-epigallocatechin; $(\bullet)(+)$-catechin; $(\triangle)(-)$-epicatechin; $(\boldsymbol{\nabla})(-)$-epigallocatechin gallate; $(\bullet)(-)$ epicatechin gallate.

and $100{ }^{\circ} \mathrm{C}$, while a longer extraction time was required at $60{ }^{\circ} \mathrm{C}$. Furthermore, the maximum concentration at $60{ }^{\circ} \mathrm{C}$ was higher than those at 80 and $100{ }^{\circ} \mathrm{C}$, which means that decomposition rate of epicatechin at $60{ }^{\circ} \mathrm{C}$ is slower than those at higher temperatures. Very similar trends were observed for epigallocatechin gallate, too (see Figure 5). In the case of epicatechin gallate, the highest maximum 

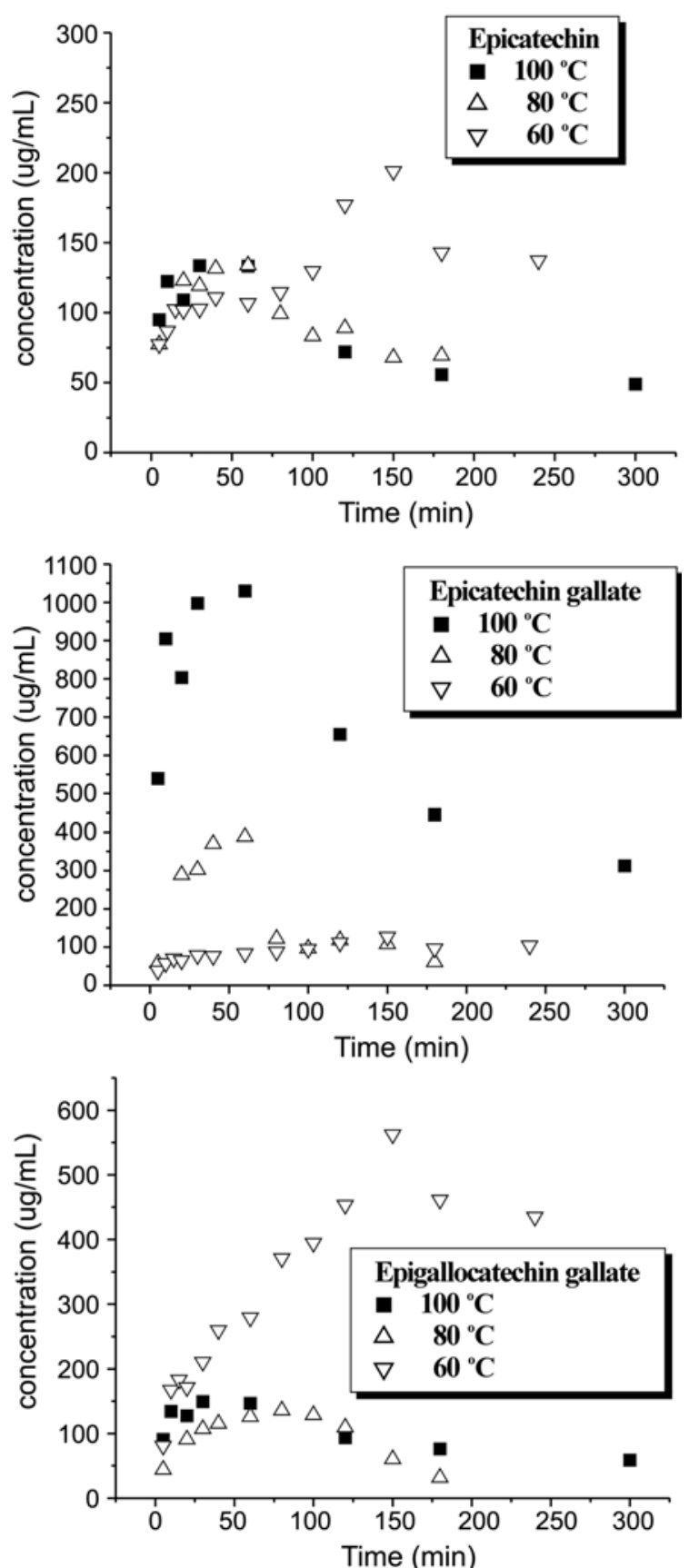

Figure 5. The effects of temperature and time on extraction from green tea leaves.

concentration was observed at $100{ }^{\circ} \mathrm{C}$ at earlier extraction time than other temperatures.

An interesting observation was appearance and growth of two unknown peaks at $100{ }^{\circ} \mathrm{C}$ on prolonged extraction. These peaks rarely showed up at 60 and $80{ }^{\circ} \mathrm{C}$. The concentration variations of the unknown peaks are shown in Figure 6. The concentration of each unknown compound increased gradually with time and reached a plateau on prolonged extraction, which means that these compounds are rather stable.

Comparison of Extraction Trends between Green Tea Leaves and Powders. The extraction trends of flavonoids
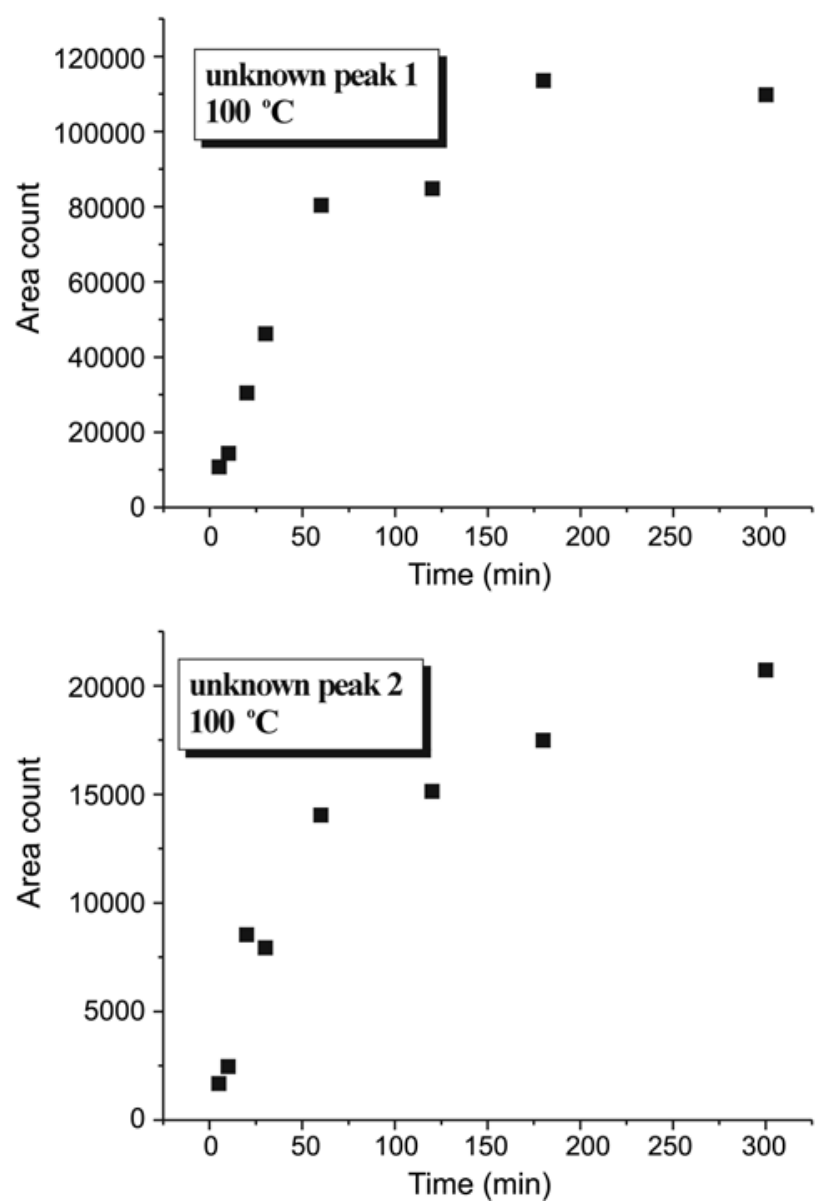

Figure 6. The Effects of time on extraction of unknown compounds.

from two different types of green tea (leaves and powders) were comparatively observed at $100{ }^{\circ} \mathrm{C}$ and shown in Figure 7. According to Figure 7, the extraction rate of green tea powders was faster than that of leaves as the green tea powders have a much wider surface area than the green tea leaves. On the other hand, faster extraction was also accompanied by faster decomposition, thus the concentration of each flavonoid (epicatechin, epicatechin gallate, epigallocatechin gallate) of green tea powders was found lower on prolonged extraction than that of green tea leaves. It is recommended by the vendor to use warm or cold water for green tea powders and to use hot water for green tea leaves.

Comparison of the First Extraction with the Second, Third and Soxhlet Extractions. It seemed interesting to examine how much flavonoids would be extracted if the green tea was filtered after the first extraction and reextracted with the same amount of water. The results of the second and third extractions in comparison with the first extraction are shown in Figure 8 (flavonoids) and Figure 9 (unknowns). The results of the Soxhlet extraction are also shown in Figure 8. The Soxhlet extraction was carried out for 24 hours, but it was marked at 350 min with an asterisk to fit the time scale of the figure.

According to Figure 8, the flavonoid concentrations of the 

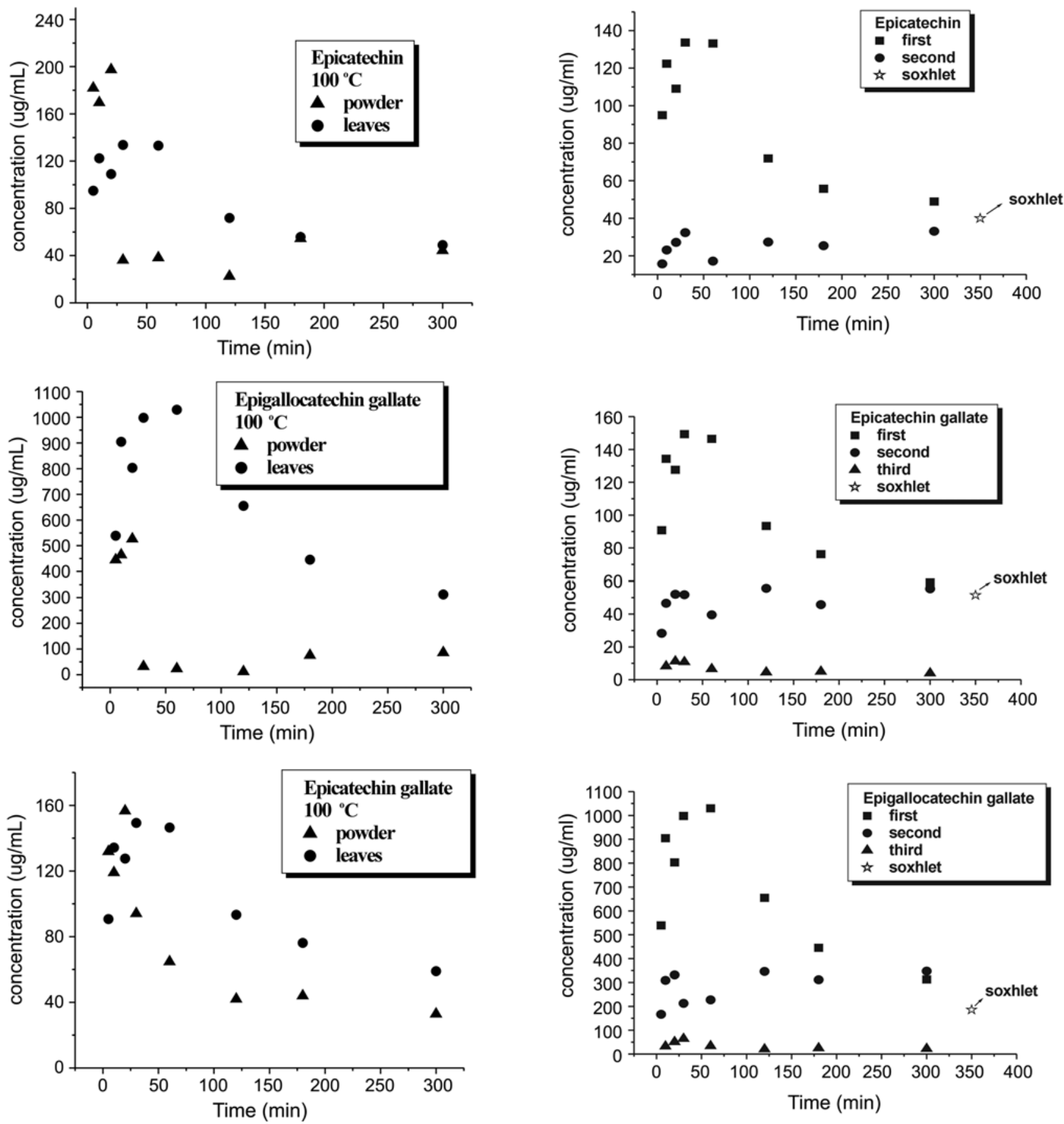

Figure 7. Comparison of two types of green tea (leaves and powders) on extraction of catechin compounds at $100{ }^{\circ} \mathrm{C}$.

first extraction were higher than those of the second extraction, and in turn, the concentrations of the second extraction, higher than those of the third extraction. The second extraction of Korean green tea seems to be somewhat useful while the third extraction is clearly not worth to carry out since the flavonoid content in the third extract was negligible.

An interesting observation in Figure 9 is that the concentrations of the unknown compounds in the second extract were higher than those in the first extract and that those in the third extract were lower than those in the first

Figure 8. Repeated extractions of catechin compounds from the green tea leaves at $100{ }^{\circ} \mathrm{C}$.

extract. We are unable to suggest any good explanation to this phenomenon for the present, but at least it is clear that the unknown compounds are not necessarily formed by decomposition of catechin compounds.

The purpose of Soxhlet extraction was to determine the total amount of each flavonoid in the green tea. As described earlier, however, the flavonoids decomposed on prolonged extraction, thus the concentrations of Soxhlet extraction were even lower than those of the second extraction. Exhaustive extraction by a Soxhlet apparatus is definitely useless for green tea. 

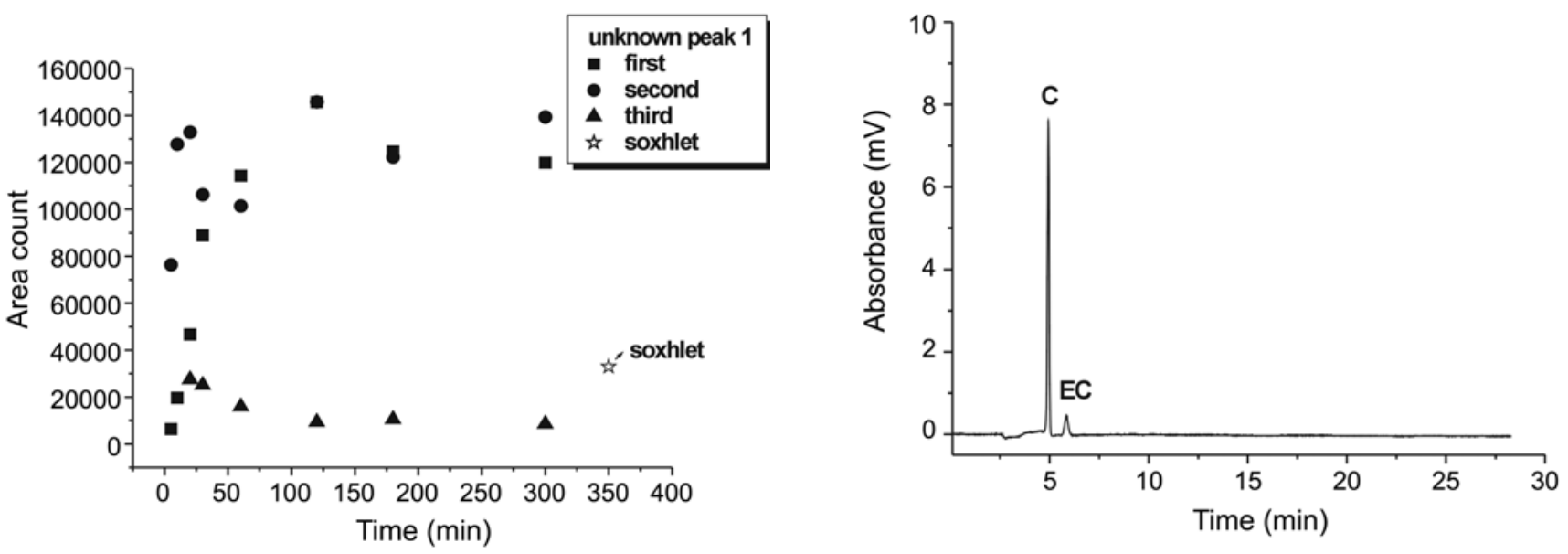

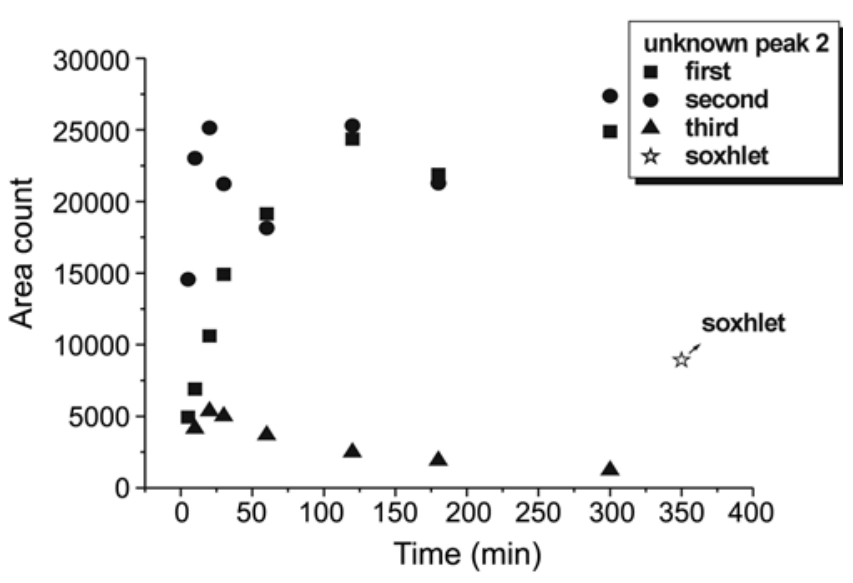

Figure 9. Repeated extractions of unknown compounds from the green tea leaves at $100^{\circ} \mathrm{C}$.

Selective Determination of Catechin and Epicatechin by Fluorescence Detection. The chromatogram of the mixture of standard catechin compounds (400 ppm) and the chromatogram of the green tea extract at $100{ }^{\circ} \mathrm{C}$ for $30 \mathrm{~min}$ are comparatively shown in Figure 10 . The Fluorescence calibration curves are given in Figure 11. The linear range of fluorescence detection was limited as shown in Figure 11, thus the real extract sample was either diluted or concentrated to give a concentration within the linear range.

Comparison between UV and Fluorescence Detection. In this study, epicatechin, epicatechin gallate, epigallocatechin gallate were determined by UV detection at 280 $\mathrm{nm}$, and catechin and epicatechin, by fluorescence detection (excitation $235 \mathrm{~nm}$, emission $315 \mathrm{~nm}$ ). Epigallocatechin was, however, unable to determine by either method. It is not fluorescent. Its UV absoptivity is also too low. The slope of its calibration curve is distinguishably low compared to those of other flavonoids as shown in Figure 4. In addition to its low sensitivity, we found by spiking of epigallocatechin that the epigallocatechin peak was surrounded by some interfering impurity peaks.

The results of fluorescence determination are given in Figure 12. The trends of the first, second, and third extractions obtained by the fluorescence detection were similar to those obtained by UV detection.

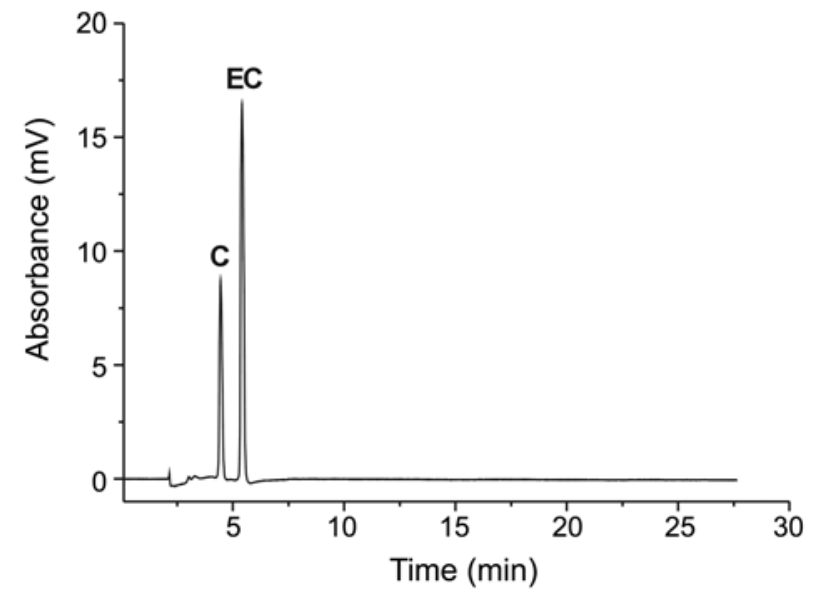

Figure 10. The Chromatograms of the standard (catechin, epicatechin, $400 \mathrm{ppm}$ ) and green tea extract at $100{ }^{\circ} \mathrm{C}$ for $30 \mathrm{~min}$ obtained by fluorescence detection with $235 \mathrm{~nm}$ excitation and 315 $\mathrm{nm}$ emission.

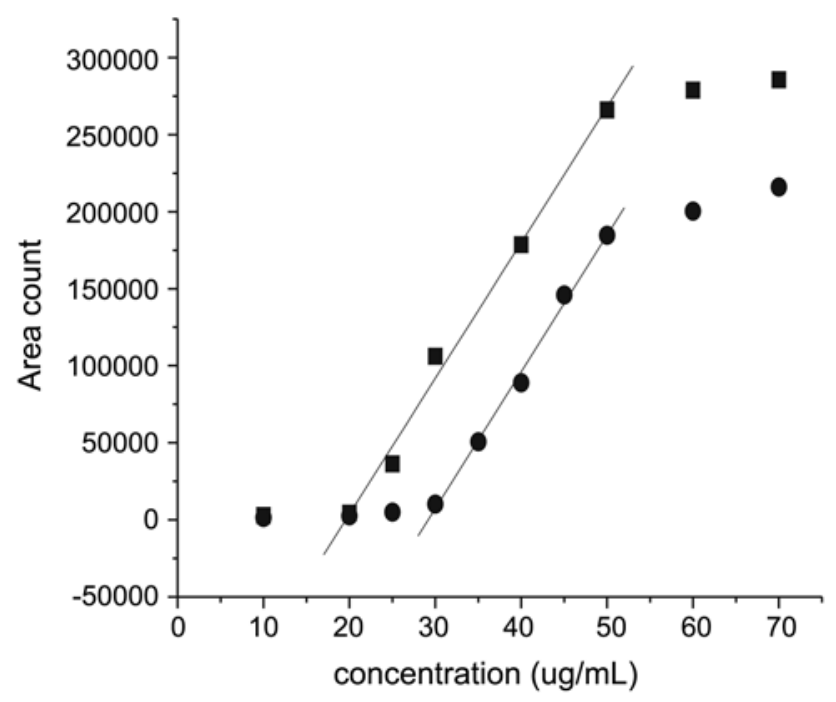

Figure 11. The calibration curves of fluorescence detection. $(\mathbf{\square})(+)$-catechin; $(\bullet)(-)$-epicatechin.

Epicatechin was determined by both UV and fluorescence detection, and the results are directly compared in Figure 13. The two sets of data were generally in agreement although 

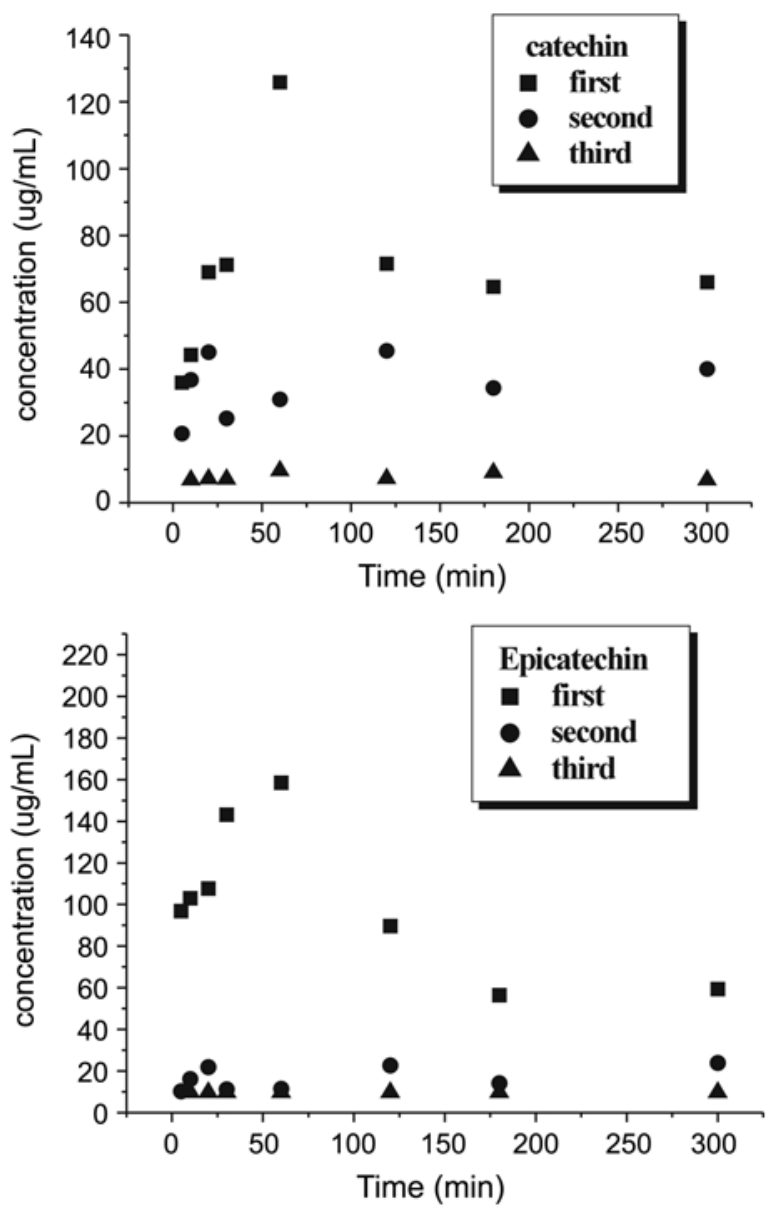

Figure 12. The results of fluorescence determination of catechin and epicatechin for repeated extractions at $100{ }^{\circ} \mathrm{C}$.

some partial discrepancies were also observed. The reliability of fluorescence data is lower than that of UV detection since fluorescence detection is less reproducible in nature and the linear range of fluorescence detection is very limited. We estimated the possible maximum amounts of individual flavonoids that can be extracted from $5 \mathrm{~g}$ Korean green tea leaves in $250 \mathrm{~mL}$ water at $100{ }^{\circ} \mathrm{C}$ on the optimum extraction time, and summarized the data in Table 1.

We measured the detection limits of UV and Fluorescence detection. The detection limits with $\mathrm{S} / \mathrm{N}$ of 5 were $15,15,3$ ppm for epigallocatechin gallate, epicatechin, and epicatechin gallate, respectively by UV detection, and $2 \mathrm{ppm}$ for catechin and epicatechin by fluorescence detection

\section{Conclusion}

Liquid chromatographic methods with UV and fluorescence detection have been used to determine types and amounts of flavonoids in typical Korean green tea extracts, and to examine the extraction efficiency of flavonoids by hot water from green tea leaves and powders with respect to extraction time and temperature. Five catechin compounds were separated by gradient elution with acetonitrile and water (including $0.1 \%$ TFA). Decomposition of flavonoids
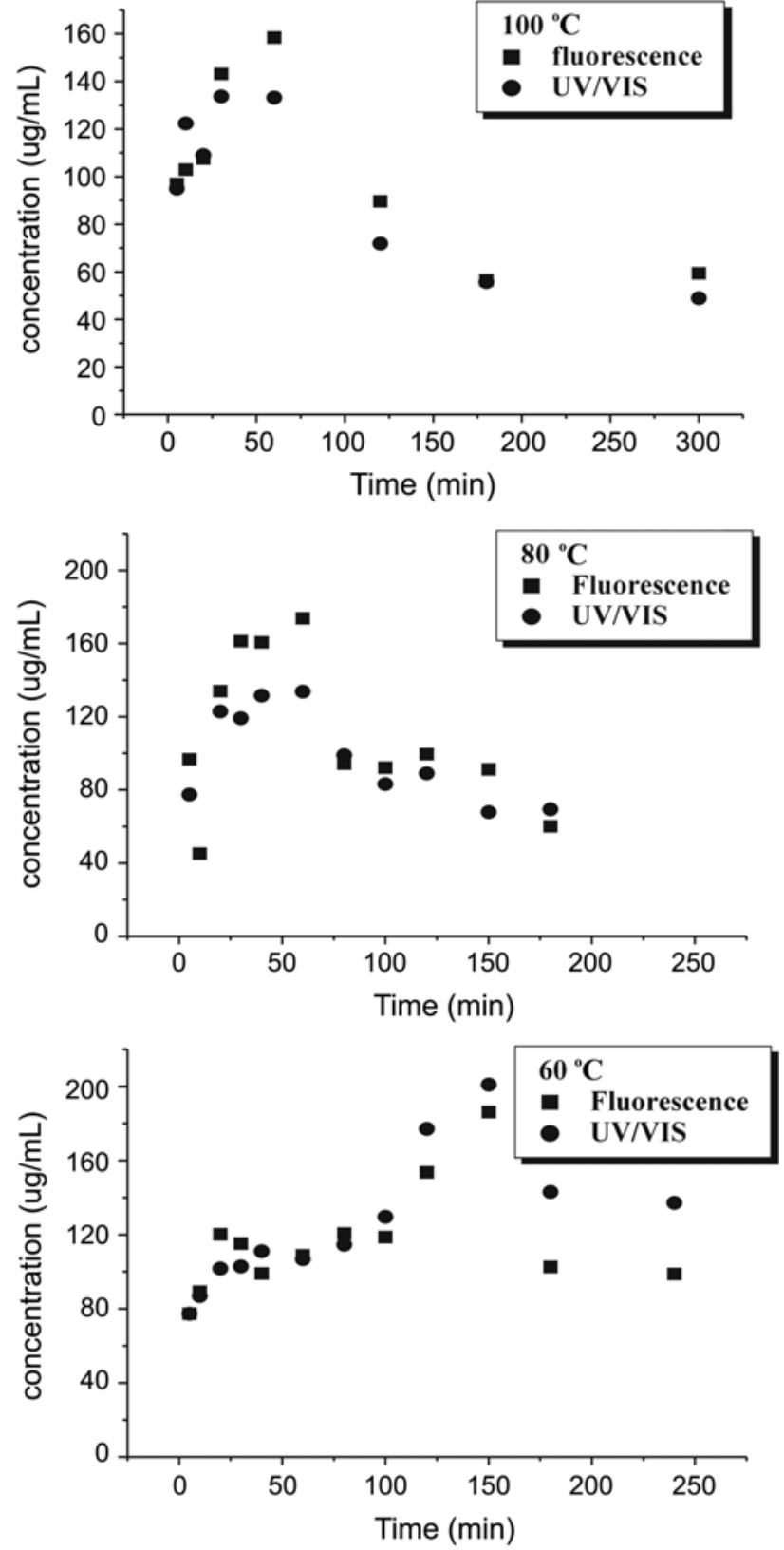

Figure 13. Comparison of UV and Fluorescence detection of epicatechin at different temperatures.

Table 1. The maximum amounts of catechin compound in the extracts $\left(100^{\circ} \mathrm{C}\right)$ from $5 \mathrm{~g}$ Korean green tea leaves

\begin{tabular}{ccc}
\hline Compound $^{a}$ & $\begin{array}{c}\mathrm{UV}(280 \mathrm{~nm}) \\
(\mathrm{mg} / \text { green tea 5 g) }\end{array}$ & $\begin{array}{c}\text { Fluorescence }(235 \mathrm{~nm}, 315 \mathrm{~nm}) \\
(\mathrm{mg} / \text { green tea 5 g) }\end{array}$ \\
\hline C & $\cdot$ & 31.5 \\
EC & 33.4 & 39.6 \\
ECG & 37.3 & $\cdot$ \\
EGC & $\cdot$ & $\cdot$ \\
EGCG & 257.4 & $\cdot$ \\
\hline
\end{tabular}

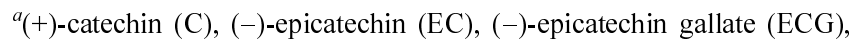
$(-)$-epigallocatechin (EGC), (-)-epigallocatechin gallate (EGCG).

in the extracts was observed, thus exhaustive extraction by a Soxhlet apparatus gave lower flavonoid concentrations than 
even the second plain extraction owing to decomposition of flavonoids. Some unknown components were found in the extracts at $100{ }^{\circ} \mathrm{C}$. It is concluded that prolonged extraction of green tea is not a good way of drinking since most of health enhancing components (flavonoids) decompose. The traditional procedure of pouring boiling water to the cup with green tea leaves and drinking it in about $10 \mathrm{~min}$ is found the proper way of drinking based on the results of this study.

Acknowledgement. This work was supported by the 2005 Inha University Fund.

\section{References}

1. Smith, H. Flavonoids in Phytochrome; Mitrakos, K, Shropshire, W., Eds.; Academic Press: New York and London, 1972; p 433.

2. Robards, K.; Antolovich, M. Analyst 1997, 122, 11R.

3. Markham, K. R. Techniques of Flavonoid Identification; Academic Press: New York and London, 1981

4. Singleton, V. L.; Esau, P. Phenolic Substances in Grapes and Wine and Their Significance; Acaedmic Press: New York, 1969.

5. Afanas'ev, I. B.; Dorozhko, A. I.; Brodskii, A. V.; Kostyuk, A.; Potapovitch, A. J. Biochem. Pharmacol. 1989, 38, 1763.

6. Mora, A.; Paya, M.; Rios, J. L.; Alcaraz, M. J. Biochem. Pharmacol. 1990, 40, 793.

7. Rice-Evans, C. A.; Miller, N. J.; Pnganga, G. Free Radical Biology and Medicine 1993, 20, 933

8. Siemann, E. H.; Creasy, L. L. Amer. J. Enol. Vitic. 1992, 43, 49

9. Jang, M.; Cai, L.; Udeani, G. O.; Slowing, K. V.; Thomas, C. F.; Beecher, C. W. W.; Fong, H. H. S.; Farnsworth, M. R.; Kinghorn, A. D.; Mehta, R. G.; Moon, R. C.; Pezzuto, J. M. Science 1997, 275,218 .

10. Middleton, E. Int. J. Pharmacog. 1996, 34, 344.

11. Steinmetz, K. A.; Porter, J. D. Cancer Causes Control 1991, 2 , 427.

12. Law, M. R.; Morris, J. K. Eur. J. Clin. Nutr. 1998, 52, 549.

13. Tijburg, L. B. M.; Mattern, T.; Folts, J. D.; Weisgerber, U. M.; Katan, M. B. Crit. Rev. Food Sci. Nutr. 1997, 37, 771.

14. Rimm, E. B.; Katan, M. B.; Ascherio, A.; Stanpfer, M. J.; Willett,
W. C. Ann. Intern. Med. 1996, 125, 384.

15. Ferry, D. R.; Smith, A.; Malkhandi, J.; Fyfe, D. W.; De Takat, P. G.; Anderson, D.; Baker, J.; Kerr, D. J. Clin. Cancer Res. 1996, 2, 659.

16. Lotito, S. B.; Fraga, C. G. Free Radical Biology and Medicine 1998, 24, 435

17. Morgan, J. F.; Klucas, R. V.; Grayer, R. J.; Abian, J.; Becana, M Free Radical Biology and Medicine 1997, 22, 861.

18. Ranabahu, P.; Harborne, J. B. Biochemical Systematics and Ecology $1993,21,715$

19. Choi, B. H. Korean J. Plant Taxonomy 1994, $24,1$.

20. Viguera, G. C.; Barberan, T. F.; Ferreres, F.; Artes, F.; Lorentes, T. F. Z. Lebensm. Unters. Forsch. 1993, 197, 255

21. Mouly, P. P.; Gaydou, E. M.; Estienne, J. M. J. Chromatogr. 1993, 634, 1529.

22. Bronner, W. E.; Beecher, G. R. J. Chromatogr. A 1995, 705, 247.

23. Mouly, P. P.; Gaydou, E. M.; Faure, R.; Estinne, J. M. J. Agric. Food Chem. 1997, 45, 373.

24. Rodriguez, M. A.; Mnalovana, S.; Perez, J. P.; Borges, T.; GraciaMontelongo, F. J. J. Chromatogr. A 2001, 912, 249.

25. Peinado, J.; Florindo, J. Analyst 1988, 113, 555.

26. Kartnig, T.; Gobel, I. J. Chromatogr. A 1996, 740, 99.

27. Schmidt, T. J.; Merfort, I. J. Chromatogr. 1993, 634, 350.

28. Schmidt, T. J.; Merfort, I.; Willuhn, G. J. Chromatogr. A 1994, 669, 236.

29. Galletti, G. C.; Reeves, J. B. Organic Mass Spectometry 1992, 27, 226.

30. Stecher, G.; Huck, C. W.; Popp, M.; Bonn, G. K. Fresenius J. Anal. Chem. 2001, 371, 73.

31. Tolonen, A.; Uusitalo, J. Rapid Comm. Mass Spectrom. 2004, 18, 3113.

32. He, X. G. J. Chromatogr. A 2000, 880, 203.

33. Lee, M.-J.; Prabhu, S.; Meng, X.; Li, C.; Yang, C. S. Anal. Biochem. 2000, 279, 164.

34. Wright, L. P.; Aucamp, J. P.; Apostolides, Z. J. Chromatogr. A 2001, 919, 205.

35. Lee, B.-L.; Ong, C.-N. J. Chromatogr. A 2000, 881, 439.

36. Sano, M.; Tabata, M.; Suzuki, M.; Degawa, M.; Miyase, T.; Maeda-Yamamoto, M. Analyst 2001, 126, 816.

37. Tsao, R.; Deng, Z. Y. J. Chromatogr. B 2004, 812, 85.

38. Zuo, Y. G.; Chen, H.; Deng, Y. W. Talanta 2002, 57, 307.

39. Fernandez, P. L.; Pablos, F.; Martin, M.; Gonzalez, A. G. J. Agric. Food Chem. 2002, 50, 1833. 